themselves with this document which was commissioned by the Department of Health and endorsed by the Faculty of Dental Surgery and the Faculty of General Dental Practice. This sets the standard for future postgraduate training and the way in which our profession is moving. This training "provides trainees with a wider range of opportunities to develop communication, team working and clinical skills'. These opportunities include experimental learning within the workplace, coaching, mentorship, formal educational events and self-directed learning. The trainees must demonstrate achievement and readiness to progress through the stages of training, ensuring that their competence and confidence are ever increasing.

We, as a profession, need to move our thinking forward from the archaic view that at the point of gaining a BDS qualification we possess all knowledge and skills required for a whole career in dentistry. Young, new dentists, having started their career with foundation training, will be continually improving their practice and those who do not follow suit will soon be left behind.

C. Ola Liverpool

1. Committee of Postgraduate Dental Deans and Directors. A Curriculum for UK Dental Foundation Programme Training, 2006.

DOI: 10.1038/sj.bdj.1091

\section{WHO WILL PAY?}

Sir, as an orthodontist working in specialist practice I read the paper by Shah et al. ${ }^{1}$ with particular interest and a feeling of rising frustration. We are continuously improving our cross-infection control and the focus of this paper on orthodontics is relevant to this process. One should always aim to continuously improve standards for our staff and patients, but it feels like a seismic shift is approaching in the regulation of cross-infection control. As this happens, I have yet to come across examples of risk:benefit analysis, cost:benefit analysis, and in these days of global warming, carbon costings? These are three elephants in the room which this paper, as with all of the others I have read which quote various studies and committee reports, fails to mention. My suspicion is that, if they were there, they would have quoted them. Furthermore, they do not discuss from where the money will come (elephant number 4!), and how many fewer patients will be able to have treatment as a result? As I read about such proposals, I ponder how recommendations for change come about. It seems that committees of experts get together to write new advice, but in the modern climate of blame one can imagine that members would, above all, want to create rules which have the least likelihood of future blame being laid at their doorstep. Cost:benefit doesn't seem to come into the equation, unlike the deliberations of NICE.

As a small example of a reasonable question regarding cost:benefit is the use of masks. This paper quotes guidelines that a mask's main function is to protect from splatter and that they should be changed for every patient. No distinction is made between a patient having a surgical procedure or a dental exam or an elastic changed on an orthodontic appliance. As an orthodontist, I wear a mask for a session at the moment, and tie it so that I can raise or drop the mask without touching it. It takes me half a minute to change a mask and a box of 50 masks costs $£ 11.45$. Following new guidelines, if I see 50 patients in a day and if surgery overheads are, say, £100 per hour, then the total extra cost for my nurse and I just to change masks for every patient is $£ 72.90$ per day. If I work five days per week for a 45-week year, the additional cost just for compliance in mask wearing, is more than $£ 16,000$ ! Who will pay and what is the benefit? I dread to think what the additional cost of all the guidelines in the offing will be when one considers the requirements for additional space, staff, equipment, time, and energy consumption, and I can anticipate the position of the PCT that there will be no additional funding for these regulations - they will force the change but they won't pay for it. This is bound to affect the quantity and quality of publicly funded treatment available. I would like to see the BDA force a debate with government on these related issues as a part of implementation. Even if the decision is to follow exactly the same path, it might ease the frustration associated with the massive changes that will ensue.

\section{P. Huntley}

By email

1. Shah R, Collins J M, Hodge T M, Laing E R. A national study of cross infection control: 'are we clean enough'. Br Dent J 2009; 207: 267-274.

DOI: 10.1038/sj.bdj.1092

\section{WARM SALINE RINSES}

Sir, it was really admirable to read 'Hancocks' Law'1 in the editorial Does the team think? as there is the same sorry state of affairs in India, even when the Dental Council of India(DCI) is striving hard to keep unauthorised dentists and doctors at bay. I am, however, quite hopeful that the DCI's efforts will bear fruit some day.

Also interesting was the letter titled Water swishing ${ }^{2}$ stating that swishing of water $^{3}$ and oral irrigation ${ }^{4}$ are an economical and easy means of maintaining oral hygiene and reducing bleeding and gingival inflammation, especially in developing countries.

Warming the water and adding a pinch of table salt to it can enhance its efficacy to a great extent. It can reduce or even be an alternative to antiinflammatory drugs intra-orally. Its high osmolality reduces inflammation and can be microbicidal. Warm saline rinses have been used successfully in post extraction cases. We have also been using it in post surgical periodontal cases for many years and the results have been excellent.

Thus rinsing with $100-150 \mathrm{ml}$ of warm saline three to four times a day can be an effective method for good oral hygiene. It can be of help in the removal of loosened food particles, dead cells and mucus from the oral cavity $^{3}$ as well as in containing the local inflammatory process.

R. Malik Haryana

1. Hancocks S. Does the team think? Br Dent J 2009; 207: 301

2. Math M V B Balasubramaniam P. Water swishing. BrDent J 2009; 207: 304

3. Math M V, Balasubramaniam P. Oral health and water. Indian J Nutr Diet 2008; 45: 388-391.

4. Barnes C M, Russell C M, Reinhardt R A, Payne J $B$, Lyle D M. Comparison of irrigation to floss as an adjunct to tooth brushing: effect on bleeding, gingivitis, and supragingival plaque. J Clin Dent 2005; 16: 71-77.

DOI: 10.1038/sj.bdj.1093 